\title{
A FISIOLOGIA DO ZINCO NO SISTEMA AUDITIVO E SUAS IMPLICAÇÕES NO ZUMBIDO
}

\author{
THE PHYSIOLOGY OF ZINC IN THE AUDITORY SYSTEM AND ITS IMPLICATIONS IN TINNITUS
}

\author{
Osmar Clayton Person ${ }^{1}$ e Maria Cristina Lancia Cury Féres²
}

\begin{abstract}
${ }^{1}$ Médico Assistente. Serviço de Otorrinolaringologia. Hospital Estadual Mário Covas. Faculdade de Medicina do ABC - FMABC. ${ }^{2}$ Docente. Departamento de Oftalmologia, Otorrinolaringologia e Cirurgia de Cabeça e Pescoço. Faculdade de Medicina de Ribeirão Preto - USP.

CorRespondência: Osmar C. Person - Departamento de Oftalmologia, Otorrinolaringologia e Cirurgia de Cabeça e Pescoço. Faculdade de Medicina de Ribeirão Preto - USP. Av. Bandeirantes, 3900 - 14049-900 - Ribeirão Preto- SP - e-mail: ocperson@ig.com.br
\end{abstract}

Person OC, Féres MCLC. A fisiologia do zinco no sistema auditivo e suas implicações no zumbido. Medicina, Ribeirão Preto 2005; 38 (1): 74-81.

Resumo: O zinco é um oligoelemento essencial à homeostase humana, e embora esteja presente em quantidades mínimas no organismo, exerce importante função como componente de metaloenzimas, agindo em todos os pontos do metabolismo. É encontrado em alguns circuitos neurais, atuando como modulador em sistemas glutamatérgicos. No sistema auditivo, é bem descrito nos núcleos cocleares e na cóclea, onde atua no sistema de defesa antioxidante, sendo a enzima superóxido dismutase cobre/zinco (Cu/ZnSOD) considerada a principal linha de defesa contra a ação de radicais livres na cóclea; também exerce, segundo alguns autores, uma função protetora da orelha interna contra danos causados pela idade, ruído, isquemia e a ação de ototóxicos. Nos últimos anos, a fisiologia do zinco tem sido relacionada ao zumbido, um sintoma que afeta $17 \%$ da população geral e $33 \%$ dos idosos e é um dos grandes desafios da otorrinolaringologia na atualidade. O presente estudo aborda aspectos relevantes da fisiologia do zinco no sistema auditivo e a relação desse íon com o sintoma zumbido.

Descritores: Zinco. Zinco; fisiologia. Zumbido.

\section{1- INTRODUÇÃO}

O zinco é um metal sólido, branco azulado, praticamente insolúvel em álcool e água, mas solúvel em ácidos diluídos ${ }^{1}$.

Sua presença em músculo e fígado humano foi descrita em 1877, mas apenas em meados de 1919, após observada a riqueza relativa desse oligoelemento no leite e nos ovos, acreditou-se que ele poderia ter alguma função nutricional ${ }^{2}$.

O zinco é o segundo oligoelemento mais prevalente no organismo, apresentando-se em grandes concentrações no cérebro de mamíferos ${ }^{3}$, e funcionalmente é considerado um elemento bastante importan- te no organismo humano, sendo essencial ao lactente, ao adulto e ao idoso ${ }^{4}$.

Está relacionado, como componente de metaloenzima, virtualmente a todos os pontos do metabolismo, destacando-se na síntese de proteínas e na expressão gênica em geral. Atua como cofator na atividade funcional de 300 enzimas diferentes, inclusive em algumas envolvidas na síntese de RNA e DNA ${ }^{5}$.

Apesar de representar apenas $0,003 \%(1,4 \mathrm{a} 2,3 \mathrm{~g})$ do corpo humano, é importante componente estabilizador de macromoléculas e de membranas biológicas ${ }^{6}$. Dentre suas funções destacam-se a regulação e inicialização da resposta imune, ação como cofator enzimático, esteroidogênese e espermatogênese, me- 
tabolismo da vitamina A, estoque e liberação de insulina, metabolismo energético, síntese protéica, estabilização de macromoléculas, regulação da transcrição do DNA, divisão celular e função antioxidante ${ }^{7}$.

Em estudos experimentais e em humanos, a deficiência aguda de zinco impede a função cerebral adequada, sendo que, em períodos precoces do desenvolvimento cerebral, causa malformações. Em períodos tardios, predispõe a anormalidades microscópicas com consequente comprometimento funcional ${ }^{8}$.

Outra função de grande importância do zinco é sua participação no sistema de defesa antioxidante. $\mathrm{O}$ íon inibe as reações de propagação de radicais livres devido à síntese de metalotioneínas, que são proteínas citosólicas de baixo peso molecular (6000 a $7000 \mathrm{Da})$, e que se ligam avidamente aos radicais promovendo proteção ("scavenger") contra danos em membranas celulares?.

A presença de zinco nos tecidos foi inicialmente detectada no sistema nervoso central em estruturas do sistema límbico (amígdala e hipocampo), e posteriormente nas camadas 1, 3 e 5 do córtex cerebral, glândula pineal ${ }^{9}$, bulbo olfatório ${ }^{10}$, núcleo coclear dorsal $^{11}$, striatum ${ }^{12}$ e cordão espinhal ${ }^{10}$.

Desde a metade do século XX, estudos têm revelado a participação do zinco na neurotransmissão central, sendo o íon encontrado em alguns circuitos neurais e relacionado ao funcionamento de redes sinápticas excitatórias glutamatérgicas ${ }^{13}$.

A função do zinco não é totalmente conhecida no tocante à neurotransmissão, embora haja conhecimento de seus efeitos neuromoduladores in vitro, incluindo inibição de receptores NMDA (N-metil-Daspartato) e GABA (ácido gama- aminobutírico) ${ }^{14}$, potencialização das respostas dos receptores AMPA (alfa-amino 3-hidroxi 5-metil 4-isoxazolepropiônico) ${ }^{15}$, aumento da liberação de $\mathrm{GABA}^{16}$, e inibição no transporte de glutamato ${ }^{17}$.

Alguns autores têm correlacionado a fisiologia do zinco com o aparecimento do zumbido ${ }^{18}$, um sintoma otoneurológico que afeta cerca de $17 \%$ da população geral e $33 \%$ dos idosos, e que é atualmente um dos grandes desafios da otorrinolaringologia. A administração sistêmica desse oligoelemento tem sido descrita como uma alternativa no tratamento de alguns casos de zumbido ${ }^{19}$.

\section{2- REVISÃO DE LITERATURA}

A deficiência de zinco em humanos foi primeiramente descrita por Prasad (1961) em uma popula- ção de Shiraz (Irã). Os homens iranianos com deficiência do oligoelemento apresentavam anemia, hepatoesplenomegalia, hipogonadismo, nanismo e geofagia ${ }^{20}$.

Cantero $(1989)^{1}$ ressaltou que a deficiência de zinco afeta principalmente homens, que apresentam retardo de crescimento e de desenvolvimento sexual, com redução ou abolição de pêlos pubianos e faciais, e freqüentemente têm perda de apetite, diminuição da gustação, olfato e retardo de cicatrização.

De acordo com Vallee e Falchuk $(1993)^{21}$, cerca de $99 \%$ do zinco corporal total (2 a 3 gramas em um homem de 70 kilogramas) é intracelular. Aproximadamente 30 a $40 \%$ do zinco celular total está no núcleo, $50 \%$ no citoplasma e suas organelas e o restante nas membranas ou paredes celulares. $\mathrm{O}$ zinco plasmático representa menos de $1 \%$ do total de zinco no organismo.

A suspeita de que o zinco poderia estar presente na orelha interna surgiu após a detecção de níveis elevados desse oligoelemento nos olhos, com base na origem embrionária comum do ectoderma dos olhos e da orelha interna. Estudos com tecidos da cóclea e vestíbulo evidenciaram que a orelha interna apresenta a maior concentração corporal de zinco que se conhece ${ }^{22}$.

As primeiras suspeitas de que a deficiência de zinco poderia causar alterações no sistema auditivo surgiu com as observações do Professor Robert Henkin, da Georgetown University, em 1979, que enviou uma carta ao Professor George Shambaugh Jr., de Illinois, relatando o caso de um paciente com deficiência de zinco e que apresentava diminuição do olfato, do paladar e da audição. A administração de zinco a esse paciente reverteu o quadro, havendo recuperação total das sensações ${ }^{22}$.

Em 1985, SHAMBAUGH Jr. ${ }^{22}$ sugeriu uma possível relação entre disacusia neurossensorial progressiva, semelhante à presbiacusia, porém associada à hipozincemia. Zinco suplementar dado a seus pacientes resultou em melhora do zumbido em $25 \%$ dos casos, ocorrendo também um discreto aumento na audição para tons puros em $20 \%$ dos pacientes tratados. No mesmo ano, o autor estudou um grupo de cobaias tratado com dieta pobre, porém não isenta de zinco, e observou que após 2, 4 e 8 semanas de tratamento, os níveis de zinco na coróide do olho, retina, cabelo, soro e unhas dos animais caíam progressivamente, enquanto no órgão de Corti, estria vascular, utrículo, sáculo e ampola dos canais semicirculares os níveis aumentavam bruscamente. 
Shambaugh Jr. (1986) ${ }^{23}$ observou que os níveis séricos de cobre aumentam após os 60 anos de idade, com concomitante decréscimo nos níveis corporais de zinco, o que poderia ser um fator relevante em alguns casos de presbiacusia, zumbidos e desequilíbrio corporal. Nesse contexto, Debartolo (1989) ${ }^{24}$ afirmou que pacientes com zumbido poderiam requerer seis vezes mais zinco que o mínimo recomendado diariamente na dieta.

Na busca de uma relação entre zumbido e hipozincemia, Gersdorff (1987) ${ }^{25}$, avaliou um grupo de 115 pacientes com zumbido e não pode comprovar essa relação; entretanto, não descartou a possibilidade de zumbidos intermitentes serem conseqüentes à hipozincemia.

Em outro estudo, Gersdorff et al. (1987) ${ }^{19}$ avaliaram um grupo de 27 pacientes com zumbido e hipozincemia, e obtiveram melhora do sintoma em $52 \%$ dos pacientes tratados com sulfato de zinco; os autores destacaram a melhor eficiência do tratamento em pacientes do sexo masculino e em zumbidos de característica contínua, embora, não tenham observado relação direta entre hipozincemia plasmática e o sucesso terapêutico ${ }^{22}$.

Paaske et al. (1991) ${ }^{26}$ realizaram um estudo duplo-cego randomizado com um grupo de pacientes que apresentava zumbido, na tentativa de comprovar hipozincemia e melhora clínica do sintoma com a administração de sulfato de zinco. O estudo não comprovou hipozincemia no grupo de pacientes com zumbido, embora, os níveis séricos de zinco tenham aumentado após o tratamento. Os autores não encontraram melhora clínica do sintoma com o tratamento.

No Hospital das Clínicas da Faculdade de Medicina da Universidade de São Paulo, a avaliação dos níveis séricos de zinco em um grupo de pacientes com zumbido evidenciou uma hiperzincemia relativa, e não hipozincemia, em comparação com um grupo controle. A administração sistêmica de sulfato de zinco gerou melhora do sintoma em 52,17\% dos casos. Os autores propuseram que a hiperzincemia encontrada poderia decorrer de hipoproteinemia, situação em que poderia ocorrer aumento da fração livre de zinco, visto que $90 \%$ do metal aparece ligado a proteínas no plasma; outra possibilidade seria uma hipozincemia intracelular que não se traduziria no soro ${ }^{27}$.

Uma diferença estatisticamente significante nos níveis séricos de zinco entre pacientes com zumbido e pacientes normais foi descrita por Ochi et al. (1997) ${ }^{28}$. Após a administração de zinco aos pacientes sintomá- ticos, diariamente por duas semanas, os níveis séricos do elemento aumentaram significativamente nos pacientes com zumbidos, concomitante ao decréscimo do sintoma, avaliado por meio de uma escala numérica. Os autores sugeriram haver relação entre níveis séricos baixos de zinco e pacientes com zumbido, mas lembraram que estudos preliminares sugerem que a suplementação de zinco beneficia apenas pacientes com zumbido que apresentam deficiência de zinco.

Recentemente, Arda et al. (2003) ${ }^{29}$ avaliaram um grupo de pacientes com zumbido tratado com zinco $(50 \mathrm{mg} /$ dia por 2 semanas), e compararam esse a um grupo tratado com placebo. Os autores concluíram que há uma resposta clínica favorável do zumbido quando se administra zinco ao paciente. A melhora, nesse estudo, relacionou-se à severidade do sintoma. Dos pacientes que fizeram uso do zinco, $82 \%$ referiram melhora na intensidade do zumbido, o que, segundo os autores, pode estar relacionada a uma diminuição dos radicais livres induzida pelo zinco, embora sejam necessários novos estudos sobre a relação entre zumbido e zinco para esclarecer esses achados.

Yetser et al. (2002) $)^{30}$ avaliaram um grupo de 40 pacientes com zumbido e não comprovaram hipozincemia em jovens e idosos com o sintoma em comparação a um grupo normal. Os autores também não evidenciaram mudança significativa na severidade do zumbido com a administração de zinco por 8 semanas, e referiram que a suplementação com zinco pode aliviar o zumbido em alguns pacientes idosos com suspeita de dieta pobre no íon.

Person $(2003)^{31}$ verificou melhora de $45,5 \%$ na intensidade dos zumbidos em um grupo de 22 pacientes tratados com compostos com zinco. $\mathrm{O}$ autor não comprovou hipozincemia no grupo de pacientes com zumbido quando comparado a um grupo normal, mas o tratamento aumentou significativamente os níveis séricos do oligoelemento. Um dado destacado foi o desaparecimento do sintoma tontura em todos os pacientes que apresentavam essa queixa no grupo tratado com compostos com zinco.

Mees (1983) ${ }^{32}$ destacou a importância do zinco na manutenção da ligação Na-K-ATPase. As deficiências do oligoelemento podem modificar o potencial endococlear, o que poderia alterar a eletrofisiologia da cóclea e gerar zumbido.

Rarey e Yao (1996) ${ }^{33}$, através de estudos histoquímicos em cóclea de ratos, descreveram que as maiores concentrações cocleares de zinco encontram-se na membrana de Reissner, em região poste- 
rior à estria vascular e em células do órgão de Corti, tanto células ciliadas internas como células ciliadas externas.

Fisiologicamente, o metabolismo celular produz radicais livres de oxigênio, mas o processo de envelhecimento, a que o ser humano está naturalmente exposto, acentua a produção dessas moléculas. Isso tem implicação no aumento das alterações celulares promovidas por esses radicais, que surgem como resultado da atividade das cadeias transportadoras de elétrons na mitocôndria e retículo endoplasmático ${ }^{34}$.

Há três principais grupos de radicais livres: o ânion superóxido, o peróxido de hidrogênio e o radical hidroxila ${ }^{35}$.

Quando os radicais livres de oxigênio são produzidos em excesso, as células não conseguem neutralizá-los, ocorrendo, como consequiência, a inativação de enzimas importantes, como a creatinaquinase e a NADH desidrogenase ${ }^{36}$, além da formação de radicais peroxinitrito e hidroxila em grandes quantidades. No caso dos radicais livres do tipo ânion superóxido, sua ação altera a fisiologia das enzimas dependentes de sulfidril, sendo um exemplo a Na-K-ATPase, relacionada à manutenção da bomba sódio-potássio ${ }^{34}$.

Na cóclea, o aumento nos níveis de radicais livres de oxigênio tem sido diretamente associado a danos nas células sensoriais do órgão de Corti. O zinco tem sido descrito na cóclea atuando juntamente com a enzima superóxido dismutase ( $\mathrm{Cu} / \mathrm{Zn}$ SOD), que é encontrada no citosol, e considerada a primeira linha de defesa contra a ação de radicais livres nessa área. A função da enzima é transformar o radical livre de oxigênio, através de catálise, em peróxido de hidrogênio e água, e eliminar um precursor do peroxinitrito, embora gere um precursor do radical hidroxila. A redução nos níveis de $\mathrm{Cu} / \mathrm{Zn}$ SOD tem sido associada à perda de células sensoriais da cóclea ${ }^{34}$.

São conhecidas três isoformas da superóxido dismutase, sendo a forma citosólica a mais prevalente, correspondendo a aproximadamente $75 \%$ da atividade da superóxido dismutase na cóclea e outros teci$\operatorname{dos}^{34}$. A superóxido dismutase exógena tem sido considerada como protetora da cóclea contra danos causados por ruído 37 .

Seidman et al. $(1993)^{37}$ descreveram que a superóxido dismutase apresenta efeito protetor contra as lesões cocleares provocadas por isquemia e ruído, havendo também uma proteção contra a ação de químicos ototóxicos, conforme descrito por Clerici $(1996)^{38}$.
A deficiência de magnésio e zinco acentua o efeito ototóxico da gentamicina e do ácido salicílico ${ }^{39}$. Xu et al. (1995) ${ }^{40}$ observaram que a administração de gentamicina em doses ototóxicas a cobaias gera, além de diminuição nos níveis auditivos, aumento nos níveis de zinco na perilinfa, consoante a uma diminuição nos níveis séricos de zinco, em uma relação estatisticamente significante em comparação a um grupo controle. Os autores sugeriram a ocorrência de uma redistribuição do zinco corporal, com maior fluxo para as áreas lesadas, como reação compensatória na cóclea, na tentativa de diminuir os efeitos ototóxicos.

McFadden et al. (1999) ${ }^{34}$, em estudos com camundongos, observaram que a deficiência de superóxido dismutase aumenta a vulnerabilidade da cóclea contra danos normalmente associados à idade. Os autores lembraram que as células ciliadas basais são mais sensíveis que as células ciliadas apicais quanto a danos ocasionados por radicais livres na cóclea, e que a diminuição ou eliminação de superóxido dismutase pode potencializar a morte de células ciliadas por permitir a ação direta nociva dos radicais livres.

Segundo Botti (2001) $)^{41}$, a condução do sinal elétrico pelas vias auditivas do tronco encefálico, evidenciada pela pesquisa de potenciais evocados auditivos, em pacientes com hipozincemia por Síndrome do Intestino Curto apresenta-se com atraso de latência e diminuição da amplitude da onda V. O autor destacou que o comportamento eletrofisiológico das estruturas auditivas centrais nestes pacientes apresenta-se semelhante a pacientes com zumbido.

\section{3- DISCUSSÃO}

Várias são as teorias que procuram explicar a fisiopatologia da geração e percepção do zumbido. Atualmente, é consenso tratar-se da resultante de uma atividade neural aberrante dentro das vias auditivas, geralmente de natureza excitatória, e interpretada como som pelo córtex auditivo ${ }^{42}$.

Os recentes estudos sobre a fisiologia do zinco no sistema auditivo têm evidenciado um papel relevante desse íon, tanto em nível periférico como central ${ }^{31}$.

O zinco é um importante fator modulador da resposta sináptica glutamatérgica, e sua ação afeta profundamente as sinapses excitatórias, o que obviamente pode gerar modificação na transmissão neu$\mathrm{ral}^{43}$. Além disso, concentração plasmática elevada de zinco pode aumentar a atividade da superóxido dismutase, o que pode constituir em fator protetor da 
cóclea contra os danos causados pela ação de radicais livres, além de contribuir na integridade e atividade da bomba sódio- potássio ${ }^{29}$.

Um dado intrigante é que os estudos que avaliaram a resposta clínica de pacientes com zumbido ao tratamento com zinco mostraram-se bastante discordantes quanto à eficácia desse oligoelemento no alívio do sintoma. Alguns pontos devem ser considerados na avaliação desses estudos ${ }^{31}$.

Primeiramente, a administração de zinco em pacientes com zumbido parece trazer resultados melhores quando há evidências de deficiência do oligoelemento no organismo. Ainda não há consenso quanto à melhor forma de avaliar com confiabilidade os estoques corporais de zinco ${ }^{2}$. A dosagem sérica do íon, apesar de ser a mais utilizada, até por sua maior disponibilidade, parece não ser tão fidedigna, e uma possível justificativa para essa imprecisão seria a presença do oligoelemento em concentrações tão distintas nos meios intra e extracelular ${ }^{31}$.

Considerando que a concentração de zinco no interior do eritrócito é 8 vezes maior que fora da célula, fatores como a hemólise, quando da coleta do sangue ou por aumento na degradação de eritrócitos no baço, poderiam alterar os resultados da dosagem sérica desse oligoelemento ${ }^{31}$.

Outro dado relevante é que o zinco é carreado no plasma por proteínas, principalmente a albumina, o que torna lícito supor que estados de hipoproteinemia poderiam aumentar a fração livre do íon no plasma ${ }^{27}$.

Enquanto não se estabelece qual o melhor método de avaliação dos níveis corporais de zinco, alguns autores têm considerado que a dosagem sérica do oligoelemento tem valor clínico quando baixa (hipozincemia sérica) $)^{5,31}$, mas para outros, o alto grau de suspeita clínica ainda é o melhor parâmetro na indicação da reposição de zinco².

Em meio a essa discussão, recentemente, Ochi et al. (2003) ${ }^{44}$ encontraram níveis séricos de zinco reduzidos em pacientes com zumbido e audição normal. Os autores sugeriram que hipozincemia sérica possa ocorrer em alguns pacientes com zumbido e audiometria normal. Em geral, os trabalhos até então não haviam avaliado níveis de zinco em grupos de pacientes com zumbido, distribuídos segundo sua característica audiométrica (por exemplo, um grupo de pacientes com disacusia severa e um grupo de pacientes audiometricamente normal). É desejável dar atenção aos achados desses autores em estudos clínicos futuros.
É necessário lembrar que, mesmo quando não há melhora do zumbido, os pacientes que anteriormente ao tratamento com zinco apresentavam queixa de tontura, tiveram importante melhora ou mesmo abolição desse sintoma após a administração desse oligoelemento $^{31}$.

O labirinto anterior e o labirinto posterior formam uma unidade anatômica única, já tendo sido descrito por Mees (1983) ${ }^{32}$ que o zinco, agindo nos canais de cálcio e na bomba Na-K-ATPase, pode promover uma modificação no potencial endolinfático, alterando a eletrofisiologia na cóclea.

As alterações nas concentrações de zinco na perilinfa aumentam quando se administra gentamicina em doses ototóxicas, o que segundo Xu et al. $(1995)^{40}$, poderia ocorrer por um mecanismo de defesa coclear, onde haveria aumento dos níveis de zinco intracoclear como resposta aos ataques promovidos pelos radicais livres; conforme assinalado por Hollen $(1995)^{45}$, a liberação de radicais livres durante o metabolismo celular aumenta com a idade, e pode alterar proteínas e ácidos nucléicos, causando peroxidação lipídica, com grave injúria celular. Esses achados permitem supor que o zinco possa, de alguma forma ainda desconhecida, influenciar a fisiologia do labirinto posterior, e conseqüentemente no sintoma tontura.

Não pode ser omitido, entretanto, que vários fatores podem relacionar-se à fisiopatologia do sintoma zumbido, sendo até certo ponto esperado que o mesmo tratamento gere resultados distintos, ou seja, melhore o zumbido de alguns pacientes e não influencie no sintoma de outros.

Arda et al. (2003) ${ }^{29}$ lembraram que o zumbido é um sintoma extremamente subjetivo, mas o nível de desconforto caracterizado pelo paciente é relevante no tratamento.

Considerando que a maioria das pessoas com audição normal refere sensação de zumbido em ambientes silenciosos, não é necessário haver lesão no sistema auditivo para que o sintoma seja percebido. Nesse contexto, Jastreboff $(1996)^{46}$ propôs um "modelo neurofisiológico" no qual a percepção do zumbido envolveria a participação de áreas não-auditivas, sobretudo aquelas relacionadas às emoções.

Embora seja aceito que a geração do zumbido ocorre na cóclea, sua percepção envolve centros corticais. Áreas corticais de associação estariam relacionadas ao processo de percepção do sintoma, havendo recrutamento de situações prévias significativas experimentadas pelo paciente. Isso seria análogo 
ao que ocorre quando um recém-nascido chora. Um indivíduo poderia não se incomodar com o choro, diferentemente da mãe da criança, que prontamente verificaria o porquê do choro, que estaria vinculado à representação de perigo ${ }^{47}$.

Em muitos indivíduos, após um curto período de consciência do zumbido, ocorreria processo de habituação, não havendo mais percepção do sintoma. Entretanto, em alguns casos, poderia haver um substrato emocional negativo, representado por medo, ansiedade ou tensão, com conseqüente ativação dos sistemas límbico e autonômico, o que perpetuaria a percepção do sintoma ${ }^{47}$.

Flor et al. (1995) $)^{48}$ referiram que o sistema límbico exerce papel de destaque em processos de reorganização funcional no sistema nervoso, e o zumbido pode estar inserido nesse cenário. Dessa forma, ficaria caracterizada uma individualidade, ou seja, o mesmo sintoma poderia ter significados distintos para duas pessoas, e isso poderia ter implicação na resposta clínica ao tratamento medicamentoso, seja com zinco ou qualquer outra medicação.

Nesse âmbito, sinais provenientes de um sistema poderiam relacionar-se a outros sistemas. Dependendo da associação com estados emocionais, o zumbido, com as mesmas características de intensidade e freqüência, poderia representar incômodo diferente em dois indivíduos, ou mesmo apresentar-se em um mesmo indivíduo com diferentes graus de incômodo em períodos distintos, na dependência do estado emocional ${ }^{49}$.

\section{4- COMENTÁRIOS FINAIS}

Já foi demonstrada a presença de zinco em algumas áreas do sistema nervoso central, onde o oligoelemento aparece em vesículas localizadas em neurônios pré- sinápticos de sistemas glutamatérgicos, provavelmente exercendo função moduladora na resposta excitatória. No sistema auditivo, aparece no núcleo coclear dorsal e na cóclea, onde age junto à enzima superóxido dismutase com ação protetora contra os efeitos nocivos dos radicais livres oriundos do elevado metabolismo da estria vascular.

Nas últimas duas décadas, os trabalhos que procuraram demonstrar associação entre o zinco e o sintoma zumbido mostraram resultados bastante distintos. Considerando que estudos recentes têm sugerido que múltiplos mecanismos fisiopatológicos possam estar envolvidos na geração e percepção do zumbido, e que a fisiologia do zinco no organismo humano não está plenamente elucidada, o cenário atual sugere que realmente o zinco deve ter algum ponto em comum com o sintoma zumbido nas vias auditivas e sistema nervoso central, mas trabalhos futuros, sobretudo experimentais, são desejáveis e fazem-se necessários para melhor elucidação dessa relação.

Person OC, Féres MCLC. The physiology of zinc in the auditory system and its implications in tinnitus. Medicina, Ribeirão Preto 2005; 38 (1): 74-81.

Abstract: Zinc is an essential oligoelement in the human homeostasis and although it is present in small quantities in the body, it has an important role as metaloenzyme, acting throughout the metabolism. It is found in some neural circuitry acting as a modulator in glutamatergic systems. In the auditory system it is active in the cochlear nucleus and in the cochlea, where it acts in the antioxidant systems and the copper/zinc superoxide dismutase (Cu/ZnSOD) is considered the first- line defense against free radicals damage in the cochlea. According to some authors, it has the role of protecting the cochlea against damage caused by normal aging, noise, ischemia and ototoxic drugs. In the past few years, its physiology has been associated to tinnitus, a symptom that affects $17 \%$ of the general population and $33 \%$ of the elderly population and it is actually a problem for otorhinolaryngology. The present study reviews important aspects of the physiology of zinc in the auditory system and its relationship to tinnitus.

Keywords: Zinc. Zinc; physiology. Tinnitus. 


\section{5- REFERÊNCIAS BIBLIOGRÁFICAS}

1 - Cantero BB. Estudio sobre el mecanismo de acción del zincum metalico. Homeopatia Mex 1989; 25: 2-14.

2 - Shuttleworth VS. Zinc- in perspective. Br Homoeopathic J 1986;75: 69-74.

3 - Weiss JH, Sensi SL, Koh JY. Zn2+: a novel ionic mediator of neural injury in brain disease. TIPS 2001; 1: 395-401.

4 - Cirino CG, Rached SLS, Nunes AB, Faria Filho M. Acrodermatite enteropática: A propósito de um caso. CCS 1987; 9: 17-20.

5 - Person OC, Nardi JC, Féres MCLC. A relação entre hipozincemia e zumbido. Rev Bras Otorrinolaringol 2004; 69: $361-7$.

6 - Jones CT. Distúrbios no metabolismo de oligoelementos. In: Wyngaarden JB, Smith LH, Bennett JC, editors. Cecil Tratado de medicina interna. 19a ed. Rio de Janeiro: Guanabara Koogan; 1992. p.1204-7.

7 - Fascinelli ML. Estudo da ação do zinco na teratogenicidade produzida pelo arsênio em camundongos. [Dissertação de Mestrado], Botucatu: Instituto de Biociências de Botucatu UNESP; 2001.

8 - Sandstead HH, Frederickson CJ, Penland JG. History of zinc as related to brain function. J Nutr 2000; 130 (Suppl.2): 496S-502S.

9 - Howell GA, Perez-Clausell J, Frederickson CJ. Zinc containing projections to the bed nucleus of the stria terminalis. Brain Res 1991; 562: 181-9.

10 - Jo SM, Won MH, Cole TB, Jensen MS, Palmiter RD, Danscher G. Zinc-enriched (ZEN) terminals in mouse olfactory bulb. Brain Res 2000; 865: 227-36.

11 - Féres MCLC , Cairasco NG. Descrição anatômica da presença do íon zinco nos núcleos cocleares. Rev Bras Otorrinolaringol 2003; 69: 208-13.

12 - Vincent SR, Semba K. A heavy metal marker of the developing striatal mosaic. Brain Res 1989; 45: 155-9.

13 - Botti AS, Féres MCLC. Íon zinco: presença no sistema auditivo. Rev Bras Otorrinolaringol 2003; 69: 111-6.

14 - Smart TG, Moss SJ, Xie X, Huganir RL. GABA receptors are differentially sensitive to zinc: dependence on subunit composition. Br J Pharmacol 1991; 103: 1837-9.

15 - Rassendren FA, Lory P, Pin JP, Nargeot J. Zinc has opposite effects o NMDA and non-NMDA receptors expressed in xenopus oocytes. Neuron 1990; 4: 733-40.

16 - Xie XM, Smart TG. A physiological role for endogenous zinc in rat hippocampal synaptic neurotransmission. Nature 1991; 349: 521-4.

17 - Vandenberg RJ, Mitrovic AD, Johnston GAR. Molecular basis for differential inhibition of glutamate transporter subtypes by zinc ions. Mol Pharmacol 1998;54: 189-96.
18 - Peters S, Koh J, Choi DW. Zinc selectively blocks the action of N-methyl-D-aspartate on cortical neurons. Science 1987; 236: 589-93.

19 - Gersdorff M, Robillard T, Stein F, Declaye X, Van Der Bemden S. A clinical correlation between hypozincemia and tinnitus. Arch Otorhinolaryngol 1987; 244: 190-3..

20 - Prasad AS, Halsted JA, Nadimi M. Syndrome of iron deficiency anemia, hepatosplenomegaly, hypogonadism, dwarfism and geophagia. Am J Med 1961; 31: 532-46.

21 - Vallee BL, Falchuk KH. The biochemical basis of zinc physiology. Physiol Rev 1993; 73: 79-118.

22 - Shambaugh Jr GE. Zinc and presbyacusis. Am J Otol 1985; 6: 116-7.

23 - Shambaugh Jr GE. Zinc for tinnitus, imbalance, and hearing loss in the elderly. Am J Otol 1986; 7: 476-7.

24 - Debartolo Jr HM. Z Zinc and diet for tinnitus. Am J Otol 1989; 10: 256.

25 - Gersdorff M. Epreuve de surchage an sulfate de zinc chez des patients sonffrant d'acouphènes associés à une hypozincémie. Acta Otorhinolaryngol (Belg)1987; 41: 498-505.

26 - Paaske PB, Pedersen CB, Kjems G, Sam ILK. Zinc in the management of tinnitus-placebo-controlled trial. Ann Otol Rhinol Laryngol 1991; 100: 647-9.

27 - Miniti A, Silva VAR, Almeida ER. Tratamento com sulfato de zinco em pacientes com zumbido. São Paulo: Faculdade de Medicina da USP; 1995. p.1-9. (Brochura).

28 - Ochi K, Ohashi T, Kinoshita $\mathrm{H}$. The serum zinc level in patients with tinnitus and the effect of zinc treatment. Nippon Jibiinkoka Gakkai Kaiho 1997; 100: 915-9.

29 - Arda HN, Tuncel U, Akdogan O, Ozluoglu LN. The role of zinc in the treatment of tinnitus. Otol Neurotol 2003; 24: 86-9.

30 - Yetser S, Tosun F, Satar B, Arslanhan M, Akcam T, Ozkaptan Y. The role of zinc in management of tinnitus. Auris Nasus Larynx 2002; 29: 329-33.

31 - Person OC. Avaliação dos potenciais evocados auditivos de tronco cerebral em portadores de tinnitus, antes e após tratamento com administração sistêmica de compostos com zinco. [Dissertação de Mestrado], Ribeirão Preto: Faculdade de Medicina de Ribeirão - USP; 2003.

32 - Mees K. The structural localization of $\mathrm{K}$ dependent sensitive Npase (Nak-ATPase) in the guinea pig inner ear. Acta Otolaryngol (Stockh) 1983; 95: 277-89.

33 - Rarey KE, Yao X. Localization of Cu/Zn-SOD and Mn-SOD in the rat cochlea. Acta Otolaryngol (Stockh) 1996; 116: 8335 .

34 - Macfadden SL, Ding D, Burkard RF, Jiang H, Reaume AG, Flood DG, Salvi RJ. Cu/Zn SOD deficiency potenciates hearing loss and cochlear pathology in aged 129, CD-1 mice. J Comparative Neurol 1999; 413: 101-12. 
35 - Pierson MG, Gray BH. Superoxide dismutase activity in the cochlea. Hear Res 1982; 6: 141-51.

36 - Zhang Y, Marcillat O, Giulivi C, Ernster L, Davies KJ. The oxidative inactivation of mitochondrial electron transport chain components and ATPase. J Biol Chem 1990; 265: 16330-6.

37 - Seidman MD, Quirk WS, Nuttall AL, Schweitzer VG. The protective effects of allopurinol snd superoxide dismutasepolyethylene glycol on ischemic and reperfusion- induced cochlear damage. Otolaryngol Head Neck Surg 1993; 109: 1052-6.

38 - Clerice WJ. Effects of superoxide dismutase and U74389G on acute trimethyltin- induced cochlear dysfunction. Toxicol Appl Pharmacol 1996; 136: 236-42.

39 - Henriques MM, Marvão JH, Pimentel JM. Potenciais evocados auditivos do tronco cerebral- noções básicas e correlações clínicas. Rev Port ORL 1999; 37: 49-57.

40 - Xu M, Fan Y, Gao Z, Chen J, Li J. Hearing loss and trace elements $\mathrm{Fe}^{2+}$ and $\mathrm{Zn}^{2+}$ in the perilymph and related specialties. J Otorhinolaryngol 1995; 57: 245-9.

41 - Botti AS. Avaliação dos potenciais evocados auditivos de tronco cerebral em pacientes portadores de deficiência crônica de zinco por Síndrome do Intestino Curto. [Dissertação de Mestrado], Ribeirão Preto: Faculdade de Medicina de Ribeirão Preto _ USP; 2001.

42 - Sanchez TG, Lorenzi MC, Brandão AL, Bento RF. O zumbido como instrumento de estudo das conexões centrais e da plasticidade do sistema auditivo. Rev Bras Otorrinolaringol 2002; 65: 839-49.
43 - Martinez-Quizarro FJE, Soriano JA, Lopez-Garcia C. Zinc positive boutons in the cerebral cortex of lizards show. Glutamate Imuno Reactivity. J Neurocytol 1991; 20: 834-43.

44 - Ochi K, Kinoshita H, Kenmochi M, Nishino H, Ohashi T. Zinc deficiency and tinnitus. Auris Nasus Larynx 2003; 30: S25S8.

45 - Hollen S. Free radicals in health and disease. Haematologia 1995; 26: 177-89.

46 - Jastreboff PJ, Gray WC, Gold SL. Neurophysiological approach to tinnitus patients. Am J Otol 1996; 17: 236-40.

47 - Jastreboff PJ. Phantom auditory perception (tinnitus): mechanisms of generation and perception. Neurosci Res 1990; 8: 221-54.

48 - Flor H, Elbert T, Knecht S, Wienbruch C, Pantev C, Birbaumer B, Larbig W, Taub E. Phantom-limb pain as a perceptual correlate of cortical reorganization following arm amputation. Nature 1995; 375: 482-4.

49 - Hazell JWP, Jastreboff PJ. Tinnitus I: auditory mechanisms: a model for tinnitus and hearing impairment. $J$ Otolaryngol 1990; 19: 1-5.

Recebido em 27/07/2004

Aprovado em 17/12/2004 